\title{
Rantai Perilaku untuk Meningkatkan Keterampilan Memakai Baju Berkancing pada Anak Sindrom Down
}

\author{
Rina Mirza, Salman Rizky, Rizki Ayu Wulandari, Rinda Ridanti Cryptia, Venny Kristia \\ Sembiring, Juli Indah Wahyuni \\ Program Studi Psikologi, Fakultas Psikologi, Universitas Prima Indonesia, Medan
}

\begin{abstract}
Abstrak. Sindrom Down memiliki keterlambatan dalam hal kemandirian, salah satunya adalah mengancing baju. Mengancing baju merupakan kegiatan sehari-hari yang tidak dapat dihindari. Adapun tujuan penelitian ini adalah untuk meningkatkan keterampilan memakai baju berkancing melalui penerapan rantai perilaku (behavior chains) dengan teknik forward chaining (penetapan urutan perlakuan mulai dari awal hingga target perilaku tercapai) pada anak sindrom Down di SLB-C di kota Medan). Subjek penelitian ini berjumlah empat orang anak sindrom Down (7 - 12 tahun) yang belum mampu mengancing baju secara mandiri. Penelitian ini menggunakan rancangan penelitian eksperimen Small- $N$ desain ABA. Pengaruh sebelum dan setelah diberikan intervensi diukur dengan menggunakan bantuan (prompt) sebagai dasar penilaian. Analisis keberhasilan efektivitas program menggunakan perbandingan data yang diperoleh dari hasil penilaian awal, intervensi, dan tindak lanjut. Terapi ini diberikan sebanyak 13 sesi. Hasil menunjukkan bahwa empat anak tersebut mampu untuk mengancing baju dengan menggunakan teknik forward chaining dari metode rantai perilaku. Setelah diberikan intervensi, maka terjadi peningkatan keterampilan memakai baju berkancing. Indikator dari peningkatan tersebut adalah dua anak mampu untuk mengancing baju tanpa bantuan dan dua anak lainnya mampu mengancing baju dengan sedikit bantuan instruksi secara verbal. Dengan demikian, hasil penelitian ini membuktikan bahwa rantai perilaku dengan teknik forward chaining mampu meningkatkan keterampilan memakai baju berkancing pada anak sindrom Down.
\end{abstract}

Kata Kunci: keterampilan, mengancing baju, rantai perilaku, sindrom Down

\section{Behavior Chains to Improve The Skill of Wearing Buttoned Clothes in Down Syndrome Children}

Abstract. Down syndrome has a delay in terms of independence. one of which is buttoning a shirt. Buttoning of clothes is a daily activity which cannot be avoided. Therefore the purpose of this study is to improve the skills to wear buttoned clothes through the application of behavior chains in children with Down syndrome at SLB-C Medan. The subjects of this study were four children with Down syndrome (7 - 12 years) who have not been able to button his clothes. This study was used the ABA small-N experimental design. The effect of before-after intervention measured by using "prompt" as basis of assessment. The analysis of program effectiveness based on comparison obtained from baseline, intervention, and follow up. A therapy was given in 13 sessions. The results showed that the four children were able to button their clothes using the forward chaining technique (sequential steps for achieving targeted behavior) from the behavior chains method. After the intervention was given, there was an increase in the skills to wear buttoned clothes, where two children were able to button clothes without prompt and the other two children were able to button clothes with a verbal prompt. Therefore, the results of this study prove that behavior chains with forward chaining technique can improve the skill of wearing buttoned clothes for children with Down syndrome.

Keywords: behavior chains, buttoning clothes, down syndrome, skills

Korespondensi: Rina Mirza. Email: rinamirza.psi@gmail.com 
Anak berkebutuhan khusus (ABK) memiliki gangguan perkembangan dan kelainan, sehingga memerlukan penanganan khusus (Desiningrum, 2016). Anak berkebutuhan khusus diartikan sebagai anak-anak yang memiliki karakteristik berbeda, baik secara fisik, emosi, ataupun mental dengan anak-anak lain seusianya (Atmaja, 2018). Salah satu contoh anak berkebutuhan khusus adalah sindrom Down.

Jamaris (2018) mengungkapkan bahwa sindrom Down merupakan kelainan bawaan yang secara mudah dapat diketahui dari ciriciri fisik yang tampak dari individu penyandang kelainan ini. Seperti yang diungkapkan oleh Nevid et al. (2014) bahwa anak sindrom Down memiliki tanda khas, seperti: wajah bulat dan lebar, hidung datar, mata terlihat sipit, lidah yang menonjol, tangan yang kecil dan berbentuk segi empat dengan jari-jari pendek, serta ukuran tangan dan kaki yang kecil dibandingkan keseluruhan tubuh lainnya (Dekker et al., 2018; García-Villamisar et al, 2019; Murpratiwi \& Tjakrawiralaksana, 2018).

Dengan segala keterbatasan yang ada pada anak sindrom Down, hal tersebut memengaruhi kehidupan sehari-harinya. Seperti AN, penjual kue kering di Surabaya dengan riwayat sindrom Down. Ibunya mengaku khawatir dengan kemandirian dan masa depan anaknya. Oleh karena itu, ibunya selalu berusaha untuk melatih kemandirian anaknya, serta mengajarkan anaknya untuk membuat kue kering. Hal ini dilakukan agar anaknya dapat menopang hidupnya secara mandiri (BBC News Indonesia, 2019).

Anak sindrom Down memiliki keterlambatan dalam hal kemandirian, termasuk keterampilan berpakaian. Menurut Nevid et al. (2014), hal ini dikarenakan mereka cenderung tidak terkoordinasi dan kurang memiliki tekanan otot yang cukup sehingga sulit bagi mereka untuk melakukan tugas-tugas fisik seperti anak-anak lain (Barboza et al., 2018; Esmail et al, 2020). Kesulitan yang sama juga dialami oleh anak sindrom Down di salah satu SLB-C di Medan. Hasil observasi menunjukkan bahwa beberapa anak sindrom Down mengalami kesulitan dalam memakai baju berkancing secara mandiri. Hal ini diperkuat dengan keterangan dari pihak sekolah bahwa anak didik di sana masih membutuhkan bantuan untuk memakai baju berkancing.

Berdasarkan kasus di atas, dapat disimpulkan bahwa anak sindrom Down memiliki permasalahan dalam keterampilan kemandirian, terutama dalam mengancing baju, sehingga diperlukan pelatihan khusus yang sesuai dengan karakteristik anak agar tujuan yang diinginkan dapat tercapai. Walaupun anak sindrom Down perlu dibimbing untuk belajar mandiri, namun penting juga untuk membiasakan anak melatih dirinya sendiri untuk mandiri.

Salah satu cara yang dapat dilakukan untuk melatih kemandirian anak, terutama dalam mengancing baju adalah pelatihan 
modifikasi perilaku. Menurut Martin dan Pear (2014), modifikasi perilaku adalah teknik mengubah perilaku, seperti mengubah respons terhadap stimulus melalui penguatan ataupun menghilangkan suatu perilaku yang tidak diinginkan dan mempertahankan perilaku yang diharapkan. Salah satu teknik modifikasi perilaku adalah rantai perilaku (behavior chains).

Rantai perilaku adalah suatu teknik modifikasi perilaku yang melibatkan stimulus dan respons yang berurutan secara sistematis, di mana respons terakhir diikuti oleh pemberian penguatan. Rantai perilaku terbagi dalam tiga metode: (a) total-task presentation, (b) backward, dan (c) forward chaining (Martin \& Pear, 2014).

Ketiga metode rantai perilaku tersebut memiliki fungsi dan penerapan yang berbeda. Pada total-task presentation, subjek mencoba semua tahap rantai perilaku dari awal hingga akhir rantai pada setiap uji coba dan melanjutkan dengan uji coba keseluruhan sampai subjek mampu menguasai setiap tahap rantai tugas tersebut. Metode backward chaining mengajarkan subjek untuk melakukan tugas dimulai dari tahap rantai perilaku yang paling akhir, sedangkan tahap sebelumnya dibimbing oleh peneliti. Metode forward chaining, subjek diminta untuk menyelesaikan setiap tahap rantai perilaku secara berurutan dan akan mendapatkan penguatan setelah menyelesaikan satu tahap rantai perilaku (Martin \& Pear, 2015).
Berdasarkan penelitian terdahulu, diketahui bahwa penerapan metode total-task presentation dapat memberikan peningkatan kemampuan anak dengan disabilitas intelektual berat dalam hal menyikat gigi. Kemampuan subjek meningkat setelah sembilan kali sesi pelatihan dengan jumlah latihan sebanyak tiga kali per sesi (Hapsari \& Hartiani, 2018). Marpaung (2017) dalam penelitiannya juga menyebutkan bahwa teknik forward chaining dapat meningkatkan kemampuan kehidupan sehari-hari, dalam hal ini buang air kecil dengan celana menggunakan ritsleting pada anak mental retardasi yang parah. Hal yang sama, juga diungkap Jaslinder dan Hildayani (2019) dalam penelitiannya yang menunjukkan bahwa teknik forward chaining efektif dalam meningkatkan keterampilan menggunakan kemeja pada anak dengan disabilitas intelektual.

Berdasarkan hasil penelitian sebelumnya, rantai perilaku dapat dijadikan sebagai teknik modifikasi perilaku dalam meningkatkan keterampilan kemandirian pada subjek dengan disabilitas inteligensi.

\section{Metode}

\section{Subjek penelitian}

Adapun karateristik sampel penelitian ini adalah sebagai berikut: (1) Subjek penelitian memiliki riwayat sindrom Down; (2) Rentang usia subjek penelitian antara 7 - 12 tahun; (3) Subjek tidak mampu memakai baju berkancing secara mandiri; (4) Subjek tidak mengalami 
gangguan fisik yang behubungan dengan keterampilan motorik halus; (5) Subjek tidak mengalami gangguan interaksi sosial dengan orang baru; dan (6) Subjek bersekolah di SLB-C di kota Medan. Berdasarkan kriteria di atas, diperoleh empat orang anak yang akan dijadikan sampel dalam penelitian ini.

\section{Desain penelitian}

Penelitian ini menggunakan rancangan penelitian eksperimen Small- $N$ desain ABA. Desain ABA melibatkan beberapa fase: (a) fase A, yaitu menciptakan garis dasar perilaku sebelum intervensi atau pengukuran awal (baseline); (b) fase $\mathrm{B}$, di mana subjek diberikan intervensi; dan (c) kembali pada fase A, yaitu kembalinya ke fase pengukuran awal setelah melakukan intervensi (Saville \& Buskist, 2003). Penelitian ini dimulai dengan fase A, di mana peneliti menciptakan garis dasar perilaku atau pengukuran awal yang merupakan tahap awal, bertujuan untuk melihat apakah anak mampu mengancingkan baju atau tidak. Sebelum menetapkan pengukuran awal, peneliti melakukan pendekatan kepada anak. Hal ini bertujuan agar anak nyaman saat melaksanakan program. Pengukuran awal dilakukan terlebih dahulu agar mendapatkan informasi mengenai kemampuan anak dalam mengancing baju untuk kemudian dapat melakukan tahapan intervensi.

Pengukuran awal dilakukan sebanyak empat sesi, di mana setiap sesinya dilakukan dua kali percobaan dan satu sesi berlangsung selama 30 menit. Pada setiap sesi pengukuran awal, peneliti menggunakan seragam. Peneliti juga menggunakan bantuan (prompt) untuk melaksanakan program, di mana hal ini akan menjadi dasar penilaian. Bantuan digunakan untuk membantu subjek menyelesaikan analisis tugas yang diberikan peneliti. Hal ini juga akan diberlakukan selama program intervensi berlangsung.

Berdasarkan hasil pengukuran awal, maka dilanjutkan dengan fase B, yaitu program intervensi yang dilakukan sebanyak sembilan sesi, di mana setiap sesinya dilakukan dua kali percobaan dan satu sesi berlangsung selama 30 menit. Dalam pelaksanaan program, anak akan diajarkan memakai baju berkancing secara bertahap sesuai dengan analisis tugas yang dibuat oleh peneliti, sehingga anak dapat melakukannya dengan baik sesuai dengan harapan peneliti. Anak akan mendapat bantuan sebagai dasar penilaian yang sudah dibuat oleh peneliti dan bertujuan agar membantu anak mencapai perilaku yang diinginkan peneliti dengan memberikan arahan kepada anak. Pemberian bantuan dilakukan mulai dari bantuan fisik yang secara bertahap akan menurun menjadi bantuan demonstrasi, bantuan dengan menggunakan gestur, hingga bantuan secara lisan. Pemberian bantuan ini dilakukan hingga anak tidak lagi membutuhkan bantuan apapun saat melakukan kegiatan.

Setiap kali anak berhasil melakukan perilaku yang terdapat di analisis tugas, anak 
akan diberikan penguatan positif berupa pujian, usapan kepala, dan menepukkan tangan antara dua orang secara bersama-sama (tos). Hal ini sangat membantu anak untuk meningkatkan keterampilan mengancing baju pada anak. Selanjutnya, peneliti memberikan skor setiap kali anak melakukan setiap program. Tujuan dilakukannya evaluasi guna melihat sejauh mana efektivitas pelaksanaan penelitian dan penguatan yang diberikan. Evaluasi ini dilaksanakan sebanyak tiga kali, di mana evaluasi pertama dilakukan pada sesi ketiga saat pelaksanaan intervensi, evaluasi kedua dilakukan saat sesi ketujuh pelaksanaan intervensi, serta evaluasi ketiga dilakukan saat sesi kesembilan pelaksanaan intervensi.

Fase setelah intervensi (fase A), yang disebut juga dengan fase tindak lanjut (follow up) dilakukan seminggu setelah dilaksanakannya program intervensi. Tujuan dilaksanakannya fase tindak lanjut adalah untuk melihat apakah perubahan yang dicapai anak selama program dapat dipertahankan setelah program selesai. Fase tindak lanjut ini didampingi oleh guru dan tidak dengan peneliti. Hal ini bertujuan agar anak melaksanakan program dengan baik dan mandiri tanpa bantuan peneliti.

\section{Analisis data}

Analisis data penelitian menggunakan analisis statistik deskriptif melalui penghitungan frekuensi pada setiap aspek keterampilan menggunakan kancing baju.

\section{Hasil}

\section{Pengukuran awal (baseline)}

Pada hasil pengukuran awal subjek AG (Tabel 1), dapat dilihat bahwa AG membutuhkan bantuan fisik pada tahap membuka dan mengancing baju di empat sesi awal. Perhatian AG juga mudah beralih, sehingga harus dipisahkan dari anak-anak lain, agar sesi terapi dapat berjalan dengan baik. Sementara itu, hasil pengukuran subjek OG (Tabel 2), dapat dilihat bahwa penggunaan bantuan pada subjek OG tidak ada yang menggunakan bantuan fisik. Hal ini karena OG menolak saat diberikan bantuan. Meskipun begitu, OG masih mengalami kesulitan saat menyamakan posisi kancing dan lubangnya serta pada saat mengancing baju. Hal yang paling sulit dilakukan oleh OG adalah saat memasang kancing paling bawah, sehingga OG harus menarik seragamnya ke atas agar dapat mengancingnya dengan baik.

Hasil pengukuran awal pada subjek $\mathrm{CH}$ (Tabel 3) menyatakan bahwa CH hanya mampu melakukan tahap satu dan tahap dua tanpa penggunaan bantuan fisik. Sementara itu, $\mathrm{CH}$ belum mampu untuk memasukkan lengan di lubang lengannya dengan benar, serta membuka dan memasang kancing. Subjek $\mathrm{CH}$ menunjukkan motivasi diri yang rendah, hal ini dapat dilihat saat $\mathrm{CH}$ kesulitan dalam membuka dan mengancing baju. CH kerap menyerah dan mengatakan tidak bisa melakukannya tanpa berusaha terlebih dahulu. 
Pada hasil pengukuran awal pada subjek PT (Tabel 4), dapat dilihat bahwa PT membutuhkan bantuan fisik pada tahap menyamakan posisi kancing serta memasangnya secara konsisten. Pada saat membuka kancing,
PT melakukannya dengan menariknya, bukan dengan mengambil kancing atau mendorong keluar kancingnya. Pada saat mengancing baju, PT tidak mampu untuk mengancingnya, sehingga PT menggigit kancingnya.

\section{Tabel 1}

Hasil Observasi dari Pengambilan Data Awal Subjek AG

\begin{tabular}{lcccc}
\hline \multirow{2}{*}{ Perilaku } & \multicolumn{4}{c}{ Pengukuran Awal } \\
\cline { 2 - 5 } & I & II & III & IV \\
\hline 1. Mengambil baju & 0 & 0 & 0 & 0 \\
2. Melebarkan baju yang dilipat & 3 & 3 & 3 & 0 \\
3. Membuka kancing & 4 & 4 & 4 & 4 \\
4. Memasukkan lengan kanan di lubang lengan & 0 & 0 & 0 & 0 \\
5. Memasukkan lengan kiri di lubang lengan & 0 & 0 & 0 & 0 \\
6. Menyamakan antar posisi kancing dan lubangnya & 2 & 2 & 3 & 3 \\
7. Mengancing baju & 4 & 4 & 4 & 4 \\
\hline
\end{tabular}

Catatan . Tugas $=$ memakai baju berkancing. Sistem penilaian $0=\operatorname{tanpa}$ bantuan; $1=$ bantuan verbal; 2 = bantuan gestur; 3 = bantuan dengan demonstrasi; 4 = bantuan fisik.

\section{Tabel 2}

Hasil Observasi dari Pengambilan Data Awal Subjek OG

\begin{tabular}{lllll}
\hline \multirow{2}{*}{\multicolumn{1}{c}{ Perilaku }} & \multicolumn{4}{c}{ Pengukuran Awal } \\
\cline { 2 - 5 } & I & II & III & IV \\
\hline 1. Mengambil baju & 1 & 1 & 0 & 1 \\
2. Melebarkan baju yang dilipat & 1 & 1 & 1 & 2 \\
3. Membuka kancing & 1 & 2 & 1 & 1 \\
4. Memasukkan lengan kanan di lubang lengan & 1 & 1 & 2 & 2 \\
5. Memasukkan lengan kiri di lubang lengan & 1 & 1 & 2 & 2 \\
6. Menyamakan antar posisi kancing dan lubangnya & 2 & 2 & 2 & 2 \\
7. Mengancing baju & 3 & 3 & 3 & 3 \\
\hline
\end{tabular}

Catatan. Tugas $=$ memakai baju berkancing. Sistem penilaian $0=$ tanpa bantuan; $1=$ bantuan verbal; 2 = bantuan gestur; 3 = bantuan dengan demonstrasi; 4 = bantuan fisik.

\section{Tabel 3}

Hasil Observasi dari Pengambilan Data Awal Subjek $\mathrm{CH}$

\begin{tabular}{lcccc}
\hline \multirow{2}{*}{\multicolumn{1}{c}{ Perilaku }} & \multicolumn{4}{c}{ Pengukuran Awal } \\
\cline { 2 - 5 } & I & II & III & IV \\
\hline 1. Mengambil baju & 1 & 1 & 1 & 1 \\
2. Melebarkan baju yang dilipat & 3 & 3 & 2 & 3 \\
3. Membuka kancing & 4 & 4 & 2 & 1 \\
4. Memasukkan lengan kanan di lubang lengan & 4 & 4 & 2 & 1 \\
5. Memasukkan lengan kiri di lubang lengan & 4 & 4 & 2 & 1 \\
6. Menyamakan antar posisi kancing dan lubangnya & 4 & 4 & 4 & 4 \\
7. Mengancing baju & 4 & 4 & 4 & 4 \\
\hline
\end{tabular}

Catatan. Tugas $=$ memakai baju berkancing. Sistem penilaian $0=\operatorname{tanpa}$ bantuan; $1=$ bantuan verbal; 2 = bantuan gestur; 3 = bantuan dengan demonstrasi; 4 = bantuan fisik. 


\section{Tabel 4}

Hasil Observasi dari Pengambilan Data Awal subjek PT

\begin{tabular}{llccc}
\hline \multirow{2}{*}{\multicolumn{1}{c}{ Perilaku }} & \multicolumn{4}{c}{ Pengukuran Awal } \\
\cline { 2 - 5 } & I & II & III & IV \\
\hline 1. Mengambil baju & 0 & 0 & 0 & 0 \\
2. Melebarkan baju yang dilipat & 1 & 1 & 2 & 1 \\
3. Membuka kancing & 2 & 2 & 2 & 2 \\
4. Memasukkan lengan kanan di lubang lengan & 1 & 1 & 1 & 1 \\
5. Memasukkan lengan kiri di lubang lengan & 2 & 2 & 2 & 2 \\
6. Menyamakan antar posisi kancing dan lubangnya & 4 & 4 & 4 & 4 \\
7. Mengancing baju & 4 & 4 & 4 & 4 \\
\hline
\end{tabular}

Catatan. Tugas $=$ memakai baju berkancing. Sistem penilaian $0=$ tanpa bantuan; $1=$ bantuan verbal; 2 = bantuan gestur; 3 = bantuan dengan demonstrasi; 4 = bantuan fisik.

\section{Intervensi}

Pelaksanaan intervensi dilakukan dalam sembilan sesi. Pelaksanaan intervensi diiringi penggunaan alat peraga dengan berbagai bentuk dan beragam ukuran kancing (besar, sedang, dan kecil) untuk melatih kemampuan subjek dalam mengancing baju. Seperti penelitian Ngatur (2016) yang mengungkapkan bahwa penggunaan alat peraga dalam proses belajar mengajar mampu meningkatkan penalaran siswa terhadap konsep yang akan diajarkan. Subjek diberikan arahan dalam setiap tahap melalui pemberian bantuan. Setelah diberikan bantuan, subjek dapat melakukan hampir seluruh tahapan yang diberikan. Jika subjek mampu melakukan arahan yang diberikan, maka subjek mendapatkan penguatan berupa pujian dan menepukkan tangan antara dua orang secara bersama-sama (tos). Berikut merupakan gambaran kemampuan subjek dalam memakai baju berkancing selama sesi pelaksanaan intervensi.

Pada hasil pengukuran pelaksanaan intervensi subjekAG (Tabel5), dapat dilihat bahwa AG mengalami peningkatan besar, terutama dalam mengancing baju, walaupun waktu yang diperlukan cukup lama. Pada ketiga sesi awal pelaksanaan intervensi, AG mengalami kesulitan

\section{Tabel 5}

Hasil Pengukuran Pelaksanaan Intervensi Subjek AG

\begin{tabular}{lccccccccc}
\hline \multicolumn{1}{c}{ Perilaku } & \multicolumn{1}{c}{ Intervensi } \\
\cline { 2 - 8 } & I & II & III & IV & V & VI & VII & VIII & IX \\
\hline 1. Mengambil baju & 1 & 1 & 1 & 0 & 0 & 0 & 0 & 1 & 0 \\
2. Melebarkan baju yang dilipat & 3 & 3 & 3 & 1 & 0 & 0 & 0 & 4 & 1 \\
3. Membuka kancing & 4 & 4 & 4 & 1 & 1 & 1 & 1 & 1 & 1 \\
4. Memasukkan lengan kanan di lubang lengan & 0 & 0 & 0 & 0 & 1 & 1 & 0 & 4 & 0 \\
5. Memasukkan lengan kiri di lubang lengan & 0 & 0 & 0 & 0 & 1 & 1 & 0 & 4 & 0 \\
6. Menyamakan antar posisi kancing dan lubangnya & 2 & 2 & 2 & 2 & 0 & 1 & 0 & 0 & 0 \\
7. Mengancing baju & 4 & 4 & 4 & 4 & 1 & 1 & 1 & 1 & 1 \\
\hline
\end{tabular}

Catatan. Tugas = memakai baju berkancing. Sistem penilaian, 0 = tanpa bantuan; 1 = bantuan verbal; 2 = bantuan gestur; 3 = bantuan dengan demonstrasi; 4 = bantuan fisik. 
untuk memegang kancing. Penggunaan alat peraga dihilangkan pada sesi keenam, karena AG sudah mampu menguasai alat peraga dan fokus untuk mengancing baju kemeja.

Sementara itu, hasil pengukuran pelaksanaan intervensi subjek OG (Tabel 6) memperlihatkan bahwa OG sudah mampu memakai baju berkancing secara mandiri tanpa diberi bantuan pada sesi kesembilan. Pada saat pelaksanaan intervensi, OG lebih mampu melakukan seluruh tahap analisis tugas jika diberi bantuan dengan demonstrasi. Penggunaan alat peraga dilepas pada sesi keempat.

Pada hasil pengukuran pelaksanaan intervensi CH (Tabel 7) memperlihatkan bahwa $\mathrm{CH}$ mengalami peningkatan besar dalam memakai baju berkancing. Hal ini dapat dilihat pada sesi ketiga intervensi, bahwa bantuan yang diberikan sudah dapat turun ke bantuan gestur. Namun, CH kerap mengalami kesulitan saat mengancing bagian atas karena tidak bisa dilihat. Motivasi $\mathrm{CH}$ yang rendah dalam menyelesaikan seluruh analisis tugas dapat dilihat dari hasil pengukuran observasi $\mathrm{CH}$ yang masih membutuhkan bantuan verbal. Hal ini dikarenakan $\mathrm{CH}$ selalu menyerah saat mengancing baju walau dia belum mencobanya. Penggunaan alat peraga dihilangkan pada sesi keenam setelah $\mathrm{CH}$ mampu menguasai alat peraga.

Pada hasil pengukuran pelaksanaan intervensi PT (Tabel 8) memperlihatkan bahwa PT mengalami peningkatan paling pesat dibandingkan subjek yang lainnya. Hal ini terlihat pada sesi kelima, bahwa PT sudah mampu menyelesaikan seluruh analisis tugas tanpa bantuan dan konsisten hingga selesai pelaksanaan intervensi. Penggunaan alat peraga dihilangkan pada sesi ketiga, di mana PT sudah mampu menguasai seluruh alat peraga.

\section{Tabel 6}

Hasil Observasi dari Pelaksanaan Intervensi Subjek OG

\begin{tabular}{|c|c|c|c|c|c|c|c|c|c|}
\hline \multirow{2}{*}{ Perilaku } & \multicolumn{9}{|c|}{ Intervensi } \\
\hline & I & II & III & IV & $\mathrm{V}$ & VI & VII & VIII & IX \\
\hline 1. Mengambil baju & 0 & 0 & 0 & 0 & 0 & 0 & 0 & 0 & 0 \\
\hline 2. Melebarkan baju yang dilipat & 0 & 0 & 1 & 0 & 0 & 0 & 1 & 0 & 0 \\
\hline 3. Membuka kancing & 3 & 3 & 1 & 1 & 0 & 0 & 0 & 1 & 0 \\
\hline 4. Memasukkan lengan kanan di lubang lengan & 0 & 0 & 0 & 0 & 0 & 0 & 0 & 0 & 0 \\
\hline 5. Memasukkan lengan kiri di lubang lengan & 0 & 0 & 0 & 2 & 1 & 2 & 0 & 1 & 0 \\
\hline 6. Menyamakan antar posisi kancing dan lubangnya & 0 & 2 & 2 & 0 & 0 & 1 & 0 & 0 & 0 \\
\hline 7. Mengancing baju & 3 & 3 & 2 & 3 & 0 & 1 & 0 & 1 & 0 \\
\hline
\end{tabular}

Catatan. Tugas $=$ memakai baju berkancing. Sistem penilaian, $0=$ tanpa bantuan; $1=$ bantuan verbal; 2 = bantuan gestur; 3 = bantuan dengan demonstrasi; 4 = bantuan fisik. 


\section{Tabel 7}

Hasil Observasi dari Pelaksanaan Intervensi Subjek $\mathrm{CH}$

\begin{tabular}{lccccccccc}
\hline \multicolumn{1}{c}{ Perilaku } & \multicolumn{7}{c}{ Intervensi } \\
\cline { 2 - 9 } & I & II & III & IV & V & VI & VII & VIII & IX \\
\hline 1. Mengambil baju & 0 & 0 & 0 & 0 & 0 & 0 & 0 & 0 & 0 \\
2. Melebarkan baju yang dilipat & 2 & 2 & 1 & 1 & 0 & 0 & 1 & 0 & 1 \\
3. Membuka kancing & 4 & 4 & 2 & 1 & 1 & 0 & 1 & 0 & 1 \\
4. Memasukkan lengan kanan di lubang lengan & 3 & 2 & 1 & 1 & 0 & 2 & 1 & 0 & 0 \\
5. Memasukkan lengan kiri di lubang lengan & 1 & 1 & 2 & 1 & 0 & 0 & 1 & 0 & 0 \\
6. Menyamakan antar posisi kancing dan & 1 & 1 & 0 & 1 & 0 & 2 & 1 & 1 & 0 \\
$\quad$ lubangnya & & & & & & & & \\
7. Mengancing baju & 4 & 4 & 2 & 2 & 0 & 1 & 1 & 0 & 1 \\
\hline
\end{tabular}

\section{Tabel 8}

Hasil Observasi dari Pelaksanaan Intervensi Subjek PT

\begin{tabular}{|c|c|c|c|c|c|c|c|c|c|}
\hline \multirow{2}{*}{ Perilaku } & \multicolumn{9}{|c|}{ Intervensi } \\
\hline & I & II & III & IV & $\mathrm{V}$ & VI & VII & VIII & IX \\
\hline 1. Mengambil baju & 0 & 0 & 0 & 0 & 0 & 0 & 0 & 0 & 0 \\
\hline 2. Melebarkan baju yang dilipat & 3 & 3 & 2 & 0 & 0 & 0 & 0 & 0 & 0 \\
\hline 3. Membuka kancing & 0 & 2 & 1 & 1 & 0 & 0 & 0 & 0 & 0 \\
\hline 4. Memasukkan lengan kanan di lubang lengan & 3 & 2 & 0 & 0 & 0 & 0 & 0 & 0 & 0 \\
\hline 5. Memasukkan lengan kiri di lubang lengan & 2 & 1 & 0 & 0 & 0 & 0 & 0 & 0 & 0 \\
\hline 6. Menyamakan antar posisi kancing dan lubangnya & 2 & 2 & 1 & 1 & 0 & 0 & 0 & 0 & 0 \\
\hline 7. Mengancing baju & 4 & 4 & 2 & 1 & 0 & 0 & 0 & 0 & 0 \\
\hline
\end{tabular}

Catatan. Tugas $=$ memakai baju berkancing. Sistem penilaian, $0=\operatorname{tanpa}$ bantuan; $1=$ bantuan verbal; 2 = bantuan gestur; 3 = bantuan dengan demonstrasi; 4 = bantuan fisik.

\section{Evaluasi}

\section{Evaluasi pertama}

Evaluasi pertama dilaksanakan sesudah pelaksanaan sesi intervensi yang ketiga. Hal ini bertujuan untuk melihat sejauh mana efektivitas pelaksanaan penelitian. Setelah menjalani tiga sesi intervensi, subjek $\mathrm{CH}, \mathrm{AG}$, dan PT menunjukkan penolakan terhadap instruksi yang diberikan oleh peneliti, sehingga mereka tidak menunjukkan perubahan dalam keterampilan memakai baju berkancing. $\mathrm{CH}$ kerap mengalami tantrum (rewel) saat sesi program berlangsung, dan AG masih tidak mampu menguasai tahap mengancing baju. PT sudah bosan dengan sesi intervensi, sehingga
PT selalu menolak setiap diberikan instruksi. Sementara itu, subjek OG tidak mengalami permasalahan selama tiga sesi intervensi dilakukan.

Peneliti memutuskan untuk melakukan serah terima subjek agar keempat subjek tidak mengalami kebosanan saat melakukan intervensi. Pada tahap evaluasi ini, peneliti menyarankan kepada pengasuh dan guru di SLB-C di kota Medan agar subjek memakai baju berkancing secara mandiri untuk mempermudah jalannya proses penelitian.

\section{Evaluasi kedua}

Evaluasi kedua dilaksanakan pada intervensi ketujuh. Pada sesi evaluasi ini, 
dilihat bagaimana perkembangan keterampilan memakai baju berkancing pada subjek. Keempat subjek dinilai sudah mampu untuk memakai baju berkancing, khususnya pada tahap mengancing baju. Hal ini menunjukkan bahwa serah terima subjek terhadap subjek dinilai mampu untuk meningkatkan keterampilan subjek. Namun, subjek $\mathrm{CH}$ masih belum dapat lepas dari dukungan verbal pada tahap dua hingga tujuh, dikarenakan $\mathrm{CH}$ masih mudah menyerah saat mengancing baju tanpa mencobanya terlebih dahulu. Peneliti memutuskan untuk memberikan penguat lain agar $\mathrm{CH}$ lebih semangat saat mengikuti intervensi dengan bermain lempar tangkap bola. Permainan ini diberikan setelah melakukan wawancara dengan guru wali kelasnya tentang apa yang disukai CH. Sementara itu, AG sudah mampu untuk menyelesaikan seluruh analisis tugas, meskipun waktu yang dibutuhkan cukup lama dikarenakan perhatiannya mudah beralih. Maka dari itu, AG dipindahkan ke bagian sudut ruangan dan menghadap ke dinding untuk mengurangi perhatiannya yang mudah beralih. Sementara itu, PT dan OG tidak mengalami permasalahan selama tujuh sesi intervensi berlangsung.

\section{Evaluasi ketiga}

Evaluasi ketiga dilakukan pada sesi intervensi kesembilan untuk melihat bagaimana peningkatan keempat subjek. Dua dari empat subjek (OG, PT) sudah mampu untuk memakai baju secara mandiri tanpa dukungan, sedangkan dua subjek lainnya (CH, AG) masih membutuhkan dukungan verbal dan perilaku yang diharapkan belum terbentuk secara keseluruhan dan konsisten. Hal ini dikarenakan $\mathrm{CH}$ masih menunjukkan perilaku mudah menyerah saat tahap mengancing baju. Meskipun begitu, $\mathrm{CH}$ mampu menyelesaikan seluruh analisis tugasnya. Subjek AG juga mampu menyelesaikan seluruh analisis tugas meskipun membutuhkan waktu yang lama. Hal ini dikarenakan perhatian AG yang mudah beralih saat intervensi berlangsung. Oleh karena itu, sesi intervensi dihentikan setelah sesi kesembilan karena keempat subjek sudah mampu untuk menguasai seluruh analisis tugasnya.

\section{Tindak lanjut}

Tahapan tindak lanjut dilakukan seminggu setelah sesi pelaksanaan intervensi. Tahapan ini dilakukan untuk dapat menentukan apakah perilaku yang diharapkan dapat dipertahankan setelah program usai. Berdasarkan hasil tindak lanjut (Tabel 9), dapat dilihat bahwa perilaku yang diharapkan dari subjek $\mathrm{CH}$ dan AG belum terbentuk secara keseluruhan dan konsisten. Hal ini dapat dilihat dari Tabel 9, yang menunjukkan bahwa kedua subjek masih memerlukan bantuan verbal untuk memudahkan kedua subjek dalam menyelesaikan analisis tugasnya. Namun, kemampuan mereka dalam memakai baju berkancing sudah menunjukkan peningkatan dibandingkan sebelum menjalani intervensi. 
Dua subjek lainnya (OG, PT) sudah mampu untuk mengancing baju secara mandiri tanpa bantuan.

Hasil pada Tabel 9 menunjukkan bahwa keempat subjek sudah mampu memakai baju berkancing walau waktu yang dibutuhkan cukup lama untuk menyelesaikan seluruh analisis tugas. Hal ini dikarenakan, perhatian keempat subjek mudah beralih saat melihat ada orang baru, termasuk peneliti. Hal tersebut membuat subjek lebih fokus pada orang baru tersebut dan harus terus-menerus diingatkan untuk mengancing bajunya sampai selesai.

\section{Tabel 9}

Hasil Observasi dari Pelaksanaan Tindak Lanjut Subjek AG, OG, CH, dan PT

\begin{tabular}{lcccc}
\hline \multicolumn{1}{c}{ Perilaku } & \multicolumn{3}{c}{ Tindak Lanjut } \\
\cline { 2 - 4 } & AG & OG & CH & PT \\
\hline 1. Mengambil baju & 0 & 0 & 0 & 0 \\
2. Melebarkan baju yang dilipat & 0 & 0 & 0 & 0 \\
3. Membuka kancing & 0 & 0 & 0 & 0 \\
4. Memasukkan lengan kanan di lubang lengan & 0 & 0 & 0 & 0 \\
5. Memasukkan lengan kiri di lubang lengan & 0 & 0 & 0 & 0 \\
6. Menyamakan antar posisi kancing dan lubangnya & 0 & 0 & 0 & 0 \\
7. Mengancing baju & 1 & 0 & 1 & 0 \\
Catatan. Tugas = memakai baju berkancing. Sistem penilaian, 0 = tanpa bantuan; 1 = bantuan \\
verbal; 2 = bantuan gestur; 3 = bantuan dengan demonstrasi; 4 = bantuan fisik.
\end{tabular}

\section{Hasil modifikasi perilaku berdasarkan analisis tugas}

\section{Gambar 1}

Grafik Hasil Modifikasi Perilaku Mengambil

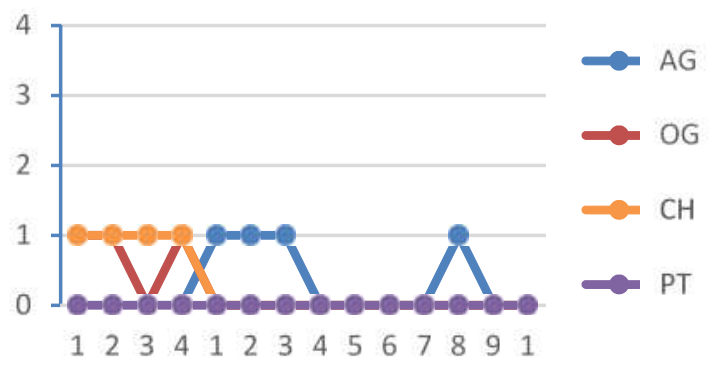

Gambar 2

Grafik Hasil Modifikasi Perilaku Melebarkan Baju yang Dilipat

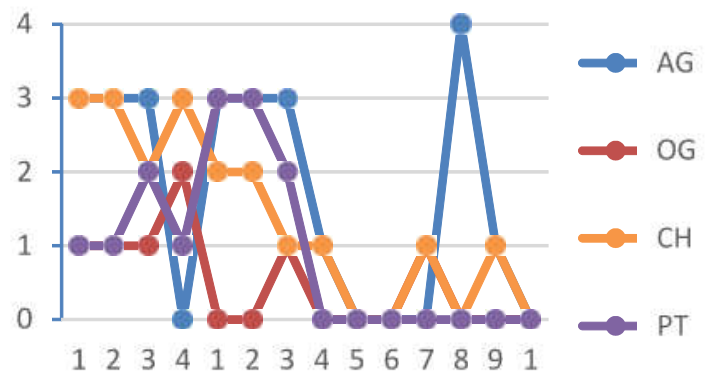

\section{Gambar 3}

Grafik Hasil Modifikasi Perilaku Membuka Kancing

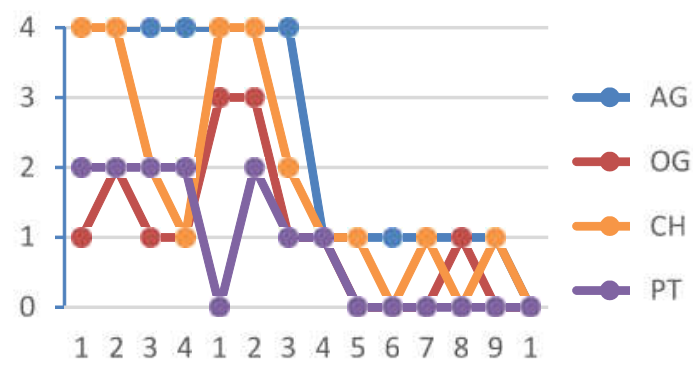

\section{Gambar 4}

Grafik Hasil Modifikasi Perilaku Memasukkan Lengan Kanan di Lubang Lengan

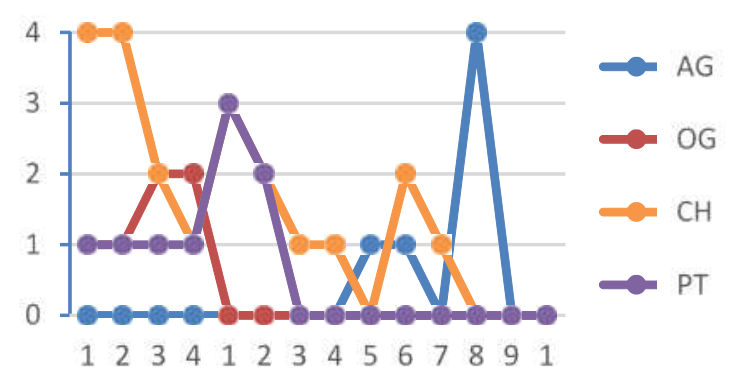




\section{Gambar 5}

Grafik Hasil Modifikasi Perilaku Memasukkan Lengan Kiri di Lubang Lengan

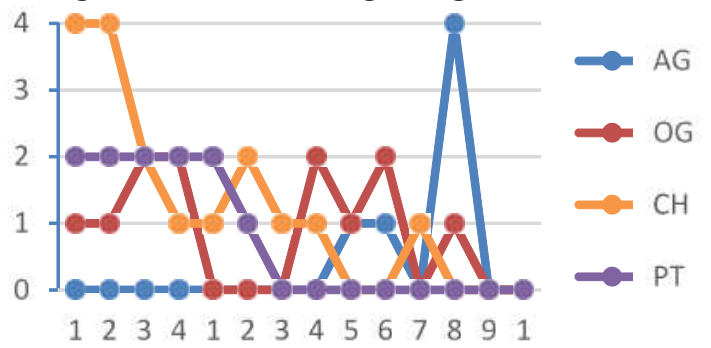

\section{Gambar 6}

Grafik Hasil Modifikasi Perilaku Menyamakan Antar Posisi Kancing dan Lubangnya

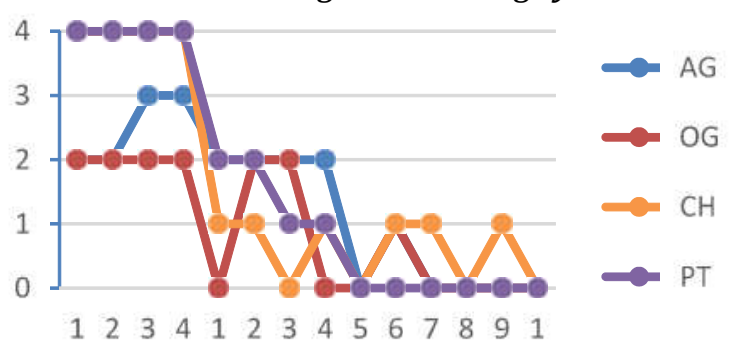

\section{Gambar 7}

Grafik Hasil Modifikasi Perilaku Mengancing Baju

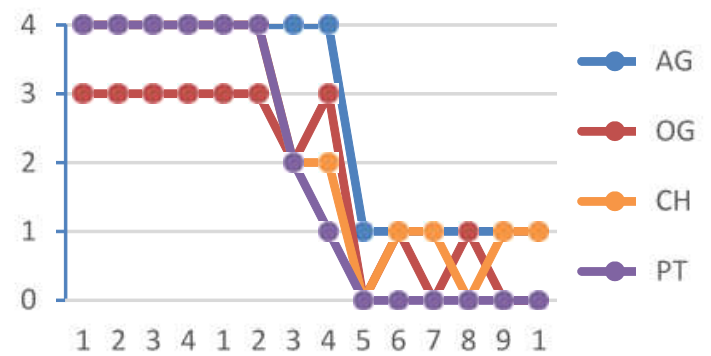

\section{Pembahasan}

Program modifikasi perilaku dengan menggunakan teknik forward chaining dinilai cukup efektif untuk meningkatkan keterampilan berpakaian, khususnya memakai baju berkancing pada anak yang mengalami disabilitas intelektual, seperti sindrom Down. Hasil penelitian ini sejalan dengan hasil penelitian sebelumnya yang menyatakan bahwa forward chaining mampu meningkatkan keterampilan berpakaian. Sebagaimana penelitian yang dilakukan oleh Natasya dan Tirta (2018), mereka menemukan bahwa teknik rantai perilaku terbukti efektif dalam meningkatkan keterampilan menggunakan baju kaus pada anak dengan disabilitas intelektual sedang. Lebih lanjut, Zain et al. (2017) juga memperoleh hasil dalam penelitiannya bahwa teknik rantai perilaku dengan menggunakan metode forward chaining dapat meningkatkan kemampuan bina diri mengancing baju.

Pemberian teknik bantuan juga dinilai efektif dalam mempermudah anak dalam mencapai target perilaku (Murpratiwi \& Tjakrawiralaksana, 2018). Namun, hal yang perlu diperhatikan adalah penggunaan bantuan yang tepat pada subjek, seperti yang terjadi pada subjek OG yang selalu menolak setiap dilakukan bantuan fisik. Peneliti harus menurunkan bantuan dengan menggunakan bantuan melalui demonstrasi untuk mencegah terjadinya pengekangan secara fisik (physical restraint). Hal ini sejalan dengan penelitian yang 
dilakukan oleh Dunlap et al. (2011) yang menyatakan bahwa pengekangan fisik tidak akan membuat perubahan apapun karena adanya pembatasan pribadi yang melumpuhkan atau mengurangi kemampuan anak sehingga membuat anak merasa ruang geraknya dibatasi (Murpratiwi \& Tjakrawiralaksana, 2018).

Meskipun keempat subjek sudah mampu memakai baju berkancing, namun perhatian keempat subjek mudah teralihkan, sehingga keempat subjek mudah kehilangan fokus saat mengancing baju, terutama pada subjek AG dan $\mathrm{CH}$ yang cukup sulit untuk kembali fokus apabila perhatiannya teralihkan. Subjek OG dan PT masih dapat kembali fokus walaupun mudah terdistraksi. Sebagaimana diutarakan Physiopedia (2019) bahwa salah satu karakteristik anak sindrom Down, yaitu: mudah terdistraksi, impulsif, sering gelisah, hingga sering mengalami kesulitan mempertahankan perhatian pada tugas. Oleh karena itu, perlu diperhatikan beberapa hal seperti ruangan yang digunakan, banyak subjek dalam ruangan, dan hal-hal lainnya untuk meminimalisir terjadinya perhatian yang mudah beralih.

Selain itu, motivasi juga memengaruhi subjek untuk meningkatkan keterampilan memakai baju berkancing. Hal ini dikarenakan $\mathrm{CH}$ memiliki motivasi yang rendah. Subjek $\mathrm{CH}$ kerap mengatakan tidak bisa setiap kali gagal dalam menyelesaikan analisis tugasnya, sehingga perkembangan $\mathrm{CH}$ untuk memakai baju berkancing secara mandiri terhitung lambat. Berbanding terbalik dengan OG dan PT yang memiliki motivasi cukup tinggi dalam mengikuti program modifikasi perilaku ini. Hal ini dibuktikan dengan mereka yang mampu memakai baju berkancing secara mandiri tanpa bantuan siapapun.

Setelah dilakukan wawancara kepada guru di SLB-C di kota Medan, ternyata perilaku $\mathrm{CH}$, yaitu motivasi rendah, dipengaruhi oleh perlakuan manja yang berlebihan yang dilakukan oleh guru sebelumnya. Menurut Dawson dan Bredehoft (2005), kemandirian anak akan terhambat jika terlalu banyak memanjakan anak-anak.

Hal lainnya juga dipengaruhi oleh keterbatasan fisik, seperti tangan mereka yang lebar dengan jari yang pendek, serta keterbatasan pada kognitif dan motorik halus. Menurut penelitian yang dilakukan oleh Puspasari et al. (2016), dengan menggunakan Nintendo WII, perbandingan anak-anak dengan keterampilan motorik halus yang rendah pada kelompok anak sindrom Down lebih tinggi dibandingkan dengan kelompok anak normal.

\section{Simpulan}

Program modifikasi perilaku dengan menggunakan forward chaining terbukti efektif dalam meningkatkan keterampilan memakai baju berkancing pada subjek dengan sindrom Down. Setelah diberi program intervensi, keterampilan subjek dalam memakai baju berkancing meningkat, di mana dua anak 
mampu untuk mengancing baju tanpa bantuan dan dua anak lainnya mampu mengancing baju dengan bantuan secara lisan. Selain itu, penggunaan alat peraga juga terbukti efektif dalam meningkatkan keterampilan memakai baju berkancing. Pemberian penghargaan juga berhasil mempertahankan motivasi subjek dalam menjalani sesi intervensi.

\section{Saran}

Saran bagi orang tua dan wali murid, diharapkan agar subjek dilatih untuk memakai baju berkancing secara mandiri walau waktu yang dibutuhkan cukup lama, serta memberikan apresiasi agar subjek semangat dalam memakai baju berkancing. Bagi guru, diharapkan agar menerapkan rantai perilaku bersamaan dengan penggunaan alat peraga pada saat pembelajaran keterampilan bina diri agar subjek tertarik pada materi yang di ajarkan, serta bagi sekolah diharapkan dapat memfasilitasi baik itu metode, alat, maupun teknik pembelajaran untuk lebih meningkatkan dan mengembangkan keterampilan pada subjek.

\section{Referensi}

Atmaja, J. R. (2018). Pendidikan dan bimbingan anak berkebutuhan khusus. Rosdakarya.

Barboza, R., Carvalho, M., Ferreira, F., \& Xu, B. (2018). Main characteristics and anthropometrics of people with down syndrome - Impact in garment design BT. In G. Di Bucchianico \& P. F. Kercher (Eds.), Advances in design for inclusion. AHFE 2017. Advances in intelligent systems and computing (pp. 417-427). Springer International Publishing. https:// doi.org/10.1007/978-3-319-605975_40
BBC News Indonesia. (2019). Kisah Aswin Nugroho penyandang down syndrome penjual kue kering yang berjuang mandiri. BBC News Indonesia. https:// www.bbc.com/indonesia/majalah47701917

Dawson, C., \& Bredehoft, D. J. (2005). The unwanted and unintended long-term results of overindulging children: Three types of overindulgence and corrective strategies for parents and institutions. In Vistas: Compelling perspectives on counseling (pp. 87-90). American Counseling Association. https:// www.counseling.org/knowledgecenter/vistas/by-year2/vistas-2005/ docs / default-source / vis tas / vistas_2005_vistas05-art18\#

Dekker, A. D., Sacco, S., Carfi, A., Benejam, B., Vermeiren, Y., Beugelsdijk, G., Schippers, M., Hassefras, L., Eleveld, J., Grefelman, S., Fopma, R., Bomer-Veenboer, M., Boti, M., Oosterling, G. D. E., Scholten, E., Tollenaere, M., Checkley, L., Strydom, A., Van Goethem, G., ... De Deyn, P. P. (2018). The Behavioral and Psychological Symptoms of Dementia in Down Syndrome (BPSD-DS) Scale: Comprehensive assessment of psychopathology in down syndrome. Journal of Alzheimer's Disease, 63, 797819. https://doi.org/10.3233/JAD170920

Desiningrum, D. R. (2016). Psikologi anak berkebutuhan khusus. Psikosain.

Dunlap, G., Ostryn, C., \& Fox, L. (2011). Preventing the use of restraint and seclusion with young children: The role of effective, positive practices. Technical Assistance Center on Social Emotional Intervention for Young Children. https:/ /eric.ed.gov/?id=ED526387

Esmail, A., Poncet, F., Auger, C., Rochette, A., Dahan-Oliel, N., Labbé, D., Kehayia, E., Billebaud, C., de Guise, É., Lessard, I., Ducharme, I., Vermeersch, 0., \& Swaine, B. (2020). The role of clothing on participation of persons with a physical disability: A scoping review. Applied 
Ergonomics, 85, 103058. https:// doi.org/10.1016/j.apergo.2020.103058

García-Villamisar, D., Álvarez-Couto, M., \& del Pozo, A. (2019). Executive functions and emotion regulation as predictors of internalising symptoms among adults with Down syndrome: A transdiagnostic perspective. Journal of Intellectual \& Developmental Disability, 1-7. https:// d o i . o r g / $\begin{array}{lllllll}1 & 0 & 3 & 1 & 0 & 9 & \text { / }\end{array}$ 13668250.2019.1669004

Hapsari, C. K., \& Hartiani, F. (2018). Penerapan prinsip modifikasi perilaku untuk meningkatkan kemampuan menyikat gigi pada anak dengan disabilitas intelektual berat. Jurnal Psikologi, 17(2), 119-130. https://doi.org/10.14710/ jp.17.2.119-130

Jamaris, M. (2018). Anak berkebutuhan khusus: Profil, asesmen, dan pelayanan pendidikan. Ghalia Indonesia.

Jaslinder, \& Hildayani, R. (2019). Efektivitas teknik forward chaining pada kemampuan menggunakan kemeja pada anak dengan disabilitas intelektual. Jurnal Psikogenesis, 7(1), 18-27. https:// doi.org/10.24854/jps.v7i1.874

Marpaung, W. (2017). Behavior modification chaining therapy untuk membentuk kemampuan daily living skill buang air kecil dengan celana menggunakan ritsleting pada anak severe mental retardation. Jurnal Poliprofesi, 12(1), 186-193. http:// publikasi.unprimdn.ac.id/posts/156behavior-modification-chainingtherapy-untuk-membentuk-kemampuandaily-lifing-skill-buang-air-kecil-dengancelana-menggunakan-ritsleting-padaanak-severe-mental-retardation-

Martin, G., \& Pear, J. (2014). Behavior modification: What it is and how to do it (10th ed.). Pearson.

Murpratiwi, I. K., \& Tjakrawiralaksana, M. A. (2018). Prompting dan positive reinforcement untuk meningkatkan keterampilan berpakaian pada anak dengan intellectual disability. Jurnal Psikologi Teori Dan Terapan, 8(2), 112-123. https:// doi.org/10.26740/jptt.v8n2.p112-123

Natasya, T. S., \& Tirta, S. (2018). Penerapan forward chaining untuk meningkatkan kemampuan memakai baju pada anak penyandang disabilitas intelektual sedang. Jurnal Muara Ilmu Sosial, Humaniora, Dan Seni, 2(1), 302-309. https://doi.org/ 10.24912/jmishumsen.v2i1.1676

Nevid, J. S., Rathus, S. A., \& Greene, B. (2014). Abnormal psychology in a changing world (9th ed.). Pearson.

Ngatur, N. (2016). Meningkatkan kemampuan memasang dan membuka kancing baju dengan menggunakan media apras bagi anak tunagrahita sedang di kelas D-1 SLB /ABC/ TPI Medan. School Education Journal PGSD FIP UNIMED, 6(1), 36-46. h t tp s: / / doi.org / 10.24114 / sejpgsd.v6i1.6001

Physiopedia. (2019). Down syndrome (Trisomy 21). Physiopedia. https://www.physio$\mathrm{p}$ e d i a . c c o $\mathrm{m}$ / Down_Syndrome_(Trisomy_21)

Puspasari, Prananta, \& Fadlyana. (2016). Score of fine motor skill in children with down syndrome using nintendo wii. Althea Medical Journal, 3(3), 371-375. https:// doi.org/10.15850/amj.v3n3.882

Saville, B. K., \& Buskist, W. (2003). Traditional idiographic approaches: Small N research designs. In S. F. Davis (Ed.), Handbook of research methods in experimental psychology (pp. 6682). Blackwell Publishing Ltd. https:/ / d o i . o r g / 100.1002 / 9780470756973.ch4

Zain, A. R., Ummah, U. S., \& Huda, A. (2017). The effect of forward chaining method towards self-help ability for wearng buttoned clothe for students with intellectual disability in the grade VII. Jurnal Penelitian Dan Pengembangan Pendidikan Luar Biasa, 4(1), 131-135. https://doi.org / 10.17977 / um029v4i22017p131 
Rina Mirza, Salman Rizky, Rizki Ayu Wulandari, Rinda Ridanti Cryptia, Venny Kristia Sembiring, Juli Indah Wahyuni

Received 5 November 2019

Revised 1 February 2020

Accepted 20 February 2020 